\title{
Assessment of Functional and Dysfunctional On Implant Stability Measurement for Quality Of Life
}

\author{
Norshahrizan Nordin ${ }^{1,}$, , Mohd Mustafa Al Bakri Abdullah ${ }^{2,3}$, Fauziah Mat $^{4}$, Muhammad \\ Abdullah $^{1}$, Razli Che Razak ${ }^{5}$, Abdul Hamid Adom ${ }^{4}$ \\ ${ }^{1}$ School of Business Innovation and Technopreneurship (PPIPT), Universiti Malaysia Perlis \\ (UniMAP), Kangar, Perlis, Malaysia \\ ${ }^{2}$ Faculty of Engineering Technology, Universiti Malaysia Perlis (UniMAP), Kangar, Malaysia \\ ${ }^{3}$ Center of Excellence Geopolymer \& Green Technology (CeGeoGTech), School of Material \\ Engineering, Universiti Malaysia Perlis (UniMAP), Perlis, Malaysia \\ ${ }^{4}$ School of Mechatronic Engineering, Universiti Malaysia Perlis (UniMAP), Pauh Putra, Perlis, \\ Malaysia \\ ${ }^{5}$ Faculty of Business and Entrepreneurship, Universiti Malaysia Kelantan (UMK), PengkalanChepa, \\ Kelantan, Malaysia
}

\begin{abstract}
This study was conducted to investigate the effect of an implant wearer comprising among orthopedic patients as well as the use of implant dentistry in Northern Malaysia. A total of 100 questionnaires were distributed and 70 questionnaires can be used to record, analyze and test hypotheses. Data for all variables were collected through a questionnaire administered alone and analyzed by using SmartPLS V3. A total of four (4) hypotheses have been formulated and the results show that the hypothesis is supported. The results show that: (1) limit the functionality and quality of life was significantly (0.904) in connection with the implant wearer, (2) physical pain was significantly $(0.845)$ relating to the quality of life, (3) physical discomfort was significantly $(0.792)$ in connection with quality of life, and also (4) social discomfort is significant as well (0.809). This finding suggests that there are positive effects on the implant wearer who through life routine. The results of the study may also serve as a basis for reliable decisions related to quality of life and for the implementation of awareness campaign that increase how the need for humanity in the field of quality involvement.
\end{abstract}

\section{Introduction}

Bone structure is the most powerful and strong structure in a body. It is harder than iron and stronger than stone. Bone consists of bonds of minerals such as calcium, phosphorus, taurine and so on. This mineral molecular bond strength determines the bone strength.

\footnotetext{
* Corresponding author: norshahrizan@uthm.edu.my
} 
Surgical services include general surgery, orthopedics, ophthalmology, otorhinolaryngology, urology, neurosurgery, plastic surgery, and various other subspecialties [1].

General surgery and orthopedic services can be found in nearly all hospital specialists. Certain services such as ophthalmology surgical specialties and sub-specialties such as vascular surgery provide network services.

\section{Implant}

The implant is medical device designs specifically for medical replace a function or structure of a part of a human body. In the field of orthopedic implants as a bone substitute is the way in restoring bone fractures. Similarly, dental implants are a way to replace missing teeth so that the function of mastication, aesthetics and comfort. A dental implant is a device that is surgically implanted into the jaw bone or soft tissue so that it can serve as a substitute root to hold the denture or bridge [2].

The restoration of dental implants is very similar to natural teeth because of embedded in the network so that it can support in terms of aesthetics, protection and development of neighboring teeth confidence. Table 1 explained about the implant is implanted in principle requires an acceptable network material body, strong enough and can work together with the restoration of the prosthesis on it [2][3]. Providing that the implants are as follows:

Table 1. Functional materials of implant [2].

Functional materials of implant

Biocompatible is defined as non-toxic, non-allergenic, non-carcinogenic, nondestructive and disruptive tissue healing around and not corrosive

Strong enough to support the weight of mastication

High resistance to thermal and corrosion

Elasticity is the same or almost the same as the surrounding tissue

Can be made in various forms

\section{Orthopedic implant}

Orthopedic implants are medical devices that are used to replace or provide fixation of bone or to replace the joint surface whether cracks, fractures or looseness. In other words, the use of orthopedic implants is used to replace damaged or problematic joints [3].

Implant surgery is also performed only by surgeons specialized and trained. For each implant surgical procedure involves removing the damaged joint replacement prostheses and artificial. These implants are mostly made of stainless steel and titanium alloy for strength and filled with plastic to act as bone substitutes or artificial [4].

However, orthopedic implants are designed differently by different manufacturers. This means that manufacturers use different design theory to develop an implant for each specific application [5]. Orthopedic implants do not only restore the quality of life but also help in mobility and reduce pain.

About restoration surgery, infection, and damage that may be part of the disadvantages of orthopedic implants. Each designed to correct orthopedic implants affected joints so it withstand movement and associated pressure and to increase mobility and reduce pain. In general, orthopedic implants available for hip, knee, shoulder and elbow [6].

The suitability of implants is referred to as the does the implant in accordance with the wearer, the implant design meets the standards or standard material used to make the 
implants. However, if the implants have a defect it will be a worse situation for the implant wearer. The Table 2 shows the implant that does not fit to the specific location of the bodies.

Table 2. Dysfunctional Materials of Implant [7].

\begin{tabular}{|l|l|}
\hline Types of dysfunctional & Explanation \\
\hline Infection & $\begin{array}{l}\text { It may occur after surgery in the early stages or after a few years. } \\
\text { Minimal infection can be treated with antibiotics. A long internal } \\
\text { infection and may require surgery and may change the bone }\end{array}$ \\
\hline Blood Clots & $\begin{array}{l}\text { It may be caused by several factors, including the lack of } \\
\text { movement of venous blood causes a slow journey. It will cause } \\
\text { swelling and pain in the affected limbs. If this happens orthopedic } \\
\text { surgeon will perform as a physical examination and laboratory } \\
\text { services and will talk to patient about treatments and methods of } \\
\text { prevention of blood clots }\end{array}$ \\
\hline Looseness Implants & $\begin{array}{l}\text { This can occur on the surface of the implant and the bone and } \\
\text { cause pain. If looseness is a problem for patients, surgery is } \\
\text { needed to convert a fake bone to another }\end{array}$ \\
\hline Transition Fake Bones & $\begin{array}{l}\text { Sometimes the implant in the bone may be moved from the } \\
\text { original. The implant can be inserted into the original place } \\
\text { without surgery. If the transition is often and cause problems for } \\
\text { patients, surgery may be done to change the new fake bones }\end{array}$ \\
\hline Wear & $\begin{array}{l}\text { Wear implant will occur in all bones false. Significant wear will } \\
\text { require surgery. }\end{array}$ \\
\hline Implant Damage & $\begin{array}{l}\text { Damage such as metal or plastic fracture in the bone fakes rare. If } \\
\text { it happens revision surgery should be done }\end{array}$ \\
\hline
\end{tabular}

\section{Dental implant}

Dental implants are made of metal objects metal shaped like a tooth and usually have a thread on the outside, installed by planted in the jaw bone (upper or lower jaw) serves to replace lost natural teeth in the mouth [8]. This system is suitable in technological developments, particularly in the field of dentistry to restore beauty, masticatory function, and the function of the pronunciation when talking. Dental implants are usually on the outer surface received additional materials that aim to get the most out of the relationship or union jawbone known as Osseo integration. Research proves this material is safe to use, can be accepted by the human body in the sense of not being rejected by the body as a foreign object or give a negative reaction, and has a maximum adaptability to the bone and soft tissue such a gums in the mouth. The process of making a dental implant was by melting the metal at very high temperatures in a vacuum or air.

Dental implants were originally designed to help patients who have lost teeth due to aging or those who have no teeth at all. However, now the dental implant treatment is given to people of all ages who have lost teeth due to various reasons, such as is involved in an accident or gum disease. However, it is rarely done on children because their jaws are not yet fully mature.

Tooth implant was shaped like a screw, produced from titanium metal (the same substance for the treatment of bone fractures) grown in the jawbone at the original place of missing teeth. It acts as a root for dentures. This method can be used to replace one tooth or several teeth. There is also a bar-shaped implants; also implanted into the jawbone. However, now more than $90 \%$ of implants available in the market around the world is shaped like a screw. Table 3 showed that dental implant does not just allow someone to eat better, but it also aims to: [10] 
Table 3. Application of dental implants [Nickenig, Wichmann, Andreas, \&Eitner (2008)].

\begin{tabular}{|l|}
\hline Dental Implants Application \\
\hline Replace one or more missing teeth without affecting adjacent teeth \\
\hline Provide support to its line of denture, making it more sturdy and \\
\hline No longer need to use removable dentures \\
\hline Help maintain the shape of the face due to missing teeth eventually cause the jaw to shrink \\
and make the bottom face looks also narrowed \\
Allowing someone to talk comfortably \\
Help restore confidence because many feel inferior and ashamed to open my mouth when \\
loss of teeth, especially the incisors. It is also important to show the image of an attractive \\
and convincing, especially for individuals who are looking for work
\end{tabular}

Dental implants can be thought of as permanent teeth because it is grown in the jawbone. When teeth come off, the jawbone shrinks slowly and it affects the soft tissue of the gums. This is why people who wear dentures have a problem matching, discomfort, often dated and difficult to chew after a certain period [8].

In Malaysia, the problem of the absence of teeth occurs at a younger age - 3\% of adults aged 35 to 44 years do not have teeth, and this figure rose to $40 \%$ (65 to 74 years) and reached $70 \%$ for senior citizens over 75 years. Furthermore, it is more than $70 \%$ of cases of tooth loss due to trauma or accident. Among individuals with no teeth, only 52\% wearing dentures even know the absence of teeth can affect their appearance [11].

\section{Theoretical framework.}

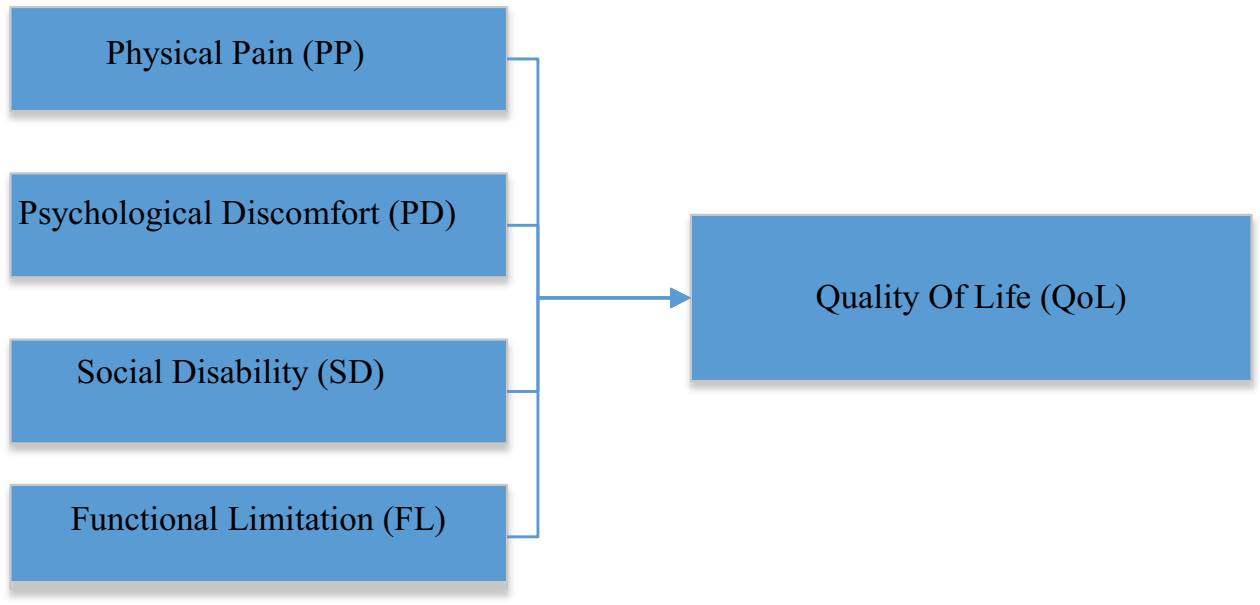

Fig.1. Theoretical Framework.

The model in Fig. 1 shows a schematic diagram of the theoretical framework creates for this study. There are four independent variables in this study which are functional limitation, physical pain, psychological discomfort and social disability. All of this is referred to as the independent variable in quality of life for users implant factors that can affect the way of life of a patient in any place either outside the home, the workplace or in the home.

While the dependent variable is the effect the way they perform their daily activities with the use of implants is whether it is positive or negative in nature. This Figure 1 also 
shows that the independent variables have a positive correlation with the dependent variable.

\section{Composite reliability}

Likewise composite reliability, all instruments shown above 0.8 except Physical Pain that performance nearly $0.8,0.792$ stated in Table 4 below:

Table 4. Composite Reliability.

\begin{tabular}{|l|l|}
\hline Functional Limitation & 0.904 \\
\hline Physical Disability & 0.845 \\
\hline Physical Pain & 0.792 \\
\hline Quality Of Life & 0.821 \\
\hline Social Discomfort & 0.809 \\
\hline
\end{tabular}

Table 4 assessed the composite reliability for functional limitation is 0.904 , physical disability is 0.845 , and social discomfort is 0.809 . These results are all above 0.8 , unlike physical pain that only 0.792 . All this result indicate to all variables to quality of life that shown 0.821 , still above 0.8 . These finding showed that the determinant factors for service design in implant stability measurement particularly on non-linear relationship should be considered for more accurate evaluation of patient needs [12]. The needs and demands of the patients must be fulfilled for them to spread a positive word of mouth. In the present scenario, a positive word of mouth plays an important role in promoting services and product [13].

\section{Average variance extracted (AVE)}

Table 5. Average Variance Extracted (AVE).

\begin{tabular}{|l|c|}
\hline Functional Limitation & 0.653 \\
\hline Physical Disability & 0.579 \\
\hline Physical Pain & 0.508 \\
\hline Quality Of Life & 0.537 \\
\hline Social Discomfort & 0.523 \\
\hline
\end{tabular}

Table 5 displayed Average Variance Extracted (AVE) of each instrument are above 0.5 as expected. The result indicated that for Functional Limitation, Physical Disability, Physical Pain, and Social Discomfort will be $0.653,0.579,0.508$, and 0.523 . Then, all instruments were proved that it is applicable to this model.

\section{Discriminant reliability towards quality of life (QoL)}

Discriminant validity value represents the cross loading factor that is to know whether the construct has sufficient discrimination quality of life that is by comparing the loading on the intended constructs must be greater than the value of the loading with other constructs. 
This is to ensure the reliability quality of life instrument is reflected to relationship has shown acceptable or not acceptable as Table 6 below.

Table 6. Discriminant Reliability.

\begin{tabular}{|l|l|l|l|l|l|}
\hline & FL & PD & PP & QOL & SD \\
\hline FL & $\mathbf{0 . 8 0 8 0 0}$ & & & & \\
\hline PD & 0.33600 & $\mathbf{0 . 7 6 1 0 0}$ & & & \\
\hline PP & 0.50600 & 0.59900 & $\mathbf{0 . 7 1 3 0 0}$ & & \\
\hline QOL & 0.31900 & 0.58900 & 0.60500 & $\mathbf{0 . 7 3 3 0 0}$ & \\
\hline SD & 0.47700 & 0.50200 & 0.54500 & 0.59100 & $\mathbf{0 . 7 2 3 0 0}$ \\
\hline
\end{tabular}

Table 6 above shown comparing the square root of the average variance extracted (AVE) correlation between each construct with other constructs in the model, if the square root of the average variance extracted (AVE) constructs larger than the correlation with all other lantern constructs then said to have good discriminant validity. Recommended the measurement must be greater than 0.50. The Functional Limitation (0.808), Physical Disability (0.761), Physical Pain (0.713), and Social Discomfort (0.723), there are every side of instruments is all above than 0.5 .

\section{Conclusion}

The implications that further increasing fulfilment of the literature on medical biostatistics terms of quality of life practices can be derived from the results of this study. The finding indicated that all the factors discussed in this study are relevant and important in predicting quality of life for implant wearer. This study also can give the authority to the management of organization in taking care of them to the quality of life for implant wearer. Likewise require attention to satisfy and motivate implant wearer in fulfilling their obligations and assisting the achievement of the life goals. Furthermore, such findings may also contribute to the additional literature for researchers to pursue and improve on, particularly in the area of humanity of medical institutions.

\section{References}

1. A. Preciado, J. Dent., 41(9), 753 (2013)

2. Y.H. Pan, T.M. Lin, C.H. Liang, Biomedical Journal, 37, (2014)

3. M. Manasas, K.Oslakovic, C. Sultan, J. Hamilton, D. Ingber, C. Sammarco, J. Kummailil, D. Skinner, U.S. Patent No. 20020128714 A1, (2001)

4. C.R. Arciola, Y.H. An, D. Campoccia, M.E. Donati, L. Montanaro, Int. J. Artif. Organs, 28, (2005)

5. C.T. Laurencin, A. Ambrosio, M. Borden, J. Cooper Jr, Annu. Rev. Biomed. Eng., 1(1), 19 (1999)

6. S. Pike, J. Van Diepenbos, J. Hazard. Mater., 47, (2003)

7. J. Schroeder, S. Goodman, K.J. Kim, Google Patents, (2006)

8. Y. F. Chen, T.H. Yang, J.H Chen, H.E. Lee, Y.C. Lin, J. Ebinger, T.M. Chou, Journal of Dental Sciences, 7(3), 289 (2012) 
9. H.J. Nickenig, M. Wichmann, S.K. Andreas, S. Eitner, J. Craniomaxillofac. Surg., 36, (2008)

10. N. Yunus, H. Abdullah, F. Hanapiah, J. Prosthet. Dent., 85, 6 (2001)

11. N. Nordin, R.C. Razak., Advanced Review on Scientific Research, 4, 1 (2014)

12. N. Nordin, A.A. Yaacob, R.C.Razak, W.N.W. Radzi, U.N. Saraih, Journal of Advanced Research in Business and Management Studies, 4, 1 (2016) 